\title{
Displacement rate effect on the flexural properties of glass fiber reinforced polyurethane
}

\author{
João Marciano Laredo dos Reis ${ }^{\text {* }}$ \\ ${ }^{a}$ Theoretical and Applied Mechanics Laboratory - LMTA, Mechanical Engineering Post-Graduate \\ Program-PGMEC, Universidade Federal Fluminense-UFF, Rua Passo da Pátria, 156, \\ CEP 24210-240, Niteroi, RJ, Brazil
}

Received: August 19, 2015; Revised: October 6, 2015; Accepted: November 26, 2015

\begin{abstract}
The object of this study was to evaluate the flexural strength of glass fiber reinforced polyurethane composites under variable displacement rates. Flexural tests have been conducted at a range of displacement rates included 0.2, 2, 20, 100, 200, $1000 \mathrm{~mm} / \mathrm{min}$. Specimens with identical geometry have been used in all the tests. This particular composite has viscoelastic behavior with both elasticity modulus and ultimate flexural strength being strongly dependent of the displacement rate. Results showed that, both the flexural modulus and the ultimate flexural strength are increased with the increasing in the displacement rate.
\end{abstract}

Keywords: Glass Fiber Reinforced Polyurethane; Flexural tests; Viscoelasticity

\section{INTRODUCTION}

Glass-fiber reinforced plastic (GFRP) laminates are used as lightweight materials in a wide variety of commercial and military structures as well as in sporting equipment. In the maritime field, for example, GFRP is used in cargo, passenger, naval ships, surfboards, canoes and racing yachts, small submersibles, on the fins and fairings of submarines, and on off-shore oil drilling platforms ${ }^{1,2}$. Besides this significant growth, the need to understands and measures the flexural parameters, which control the structure-property relationships in such composites are mandatory.

Polyurethane belongs to one of the most versatile classes of polymers and can exist as both thermosetting and thermoplastics depending upon the choice of the initial reactants. Polyurethanes have many advantages such as low viscosity, excellent bonding with the matrix material without special sizing of the fibers, relatively low price and fast reaction time. The thermoset polyurethanes are a class of polymer materials with desirable properties, such as high abrasion resistance, tear strength, excellent shock absorption, flexibility and elasticity ${ }^{3-5}$. It is a polymer composed of a chain of organic units joined by carbamate (urethane) links most commonly formed by reacting a di- or polyisocyanate with a polyol. Both the isocyanates and polyols used to make polyurethanes contain on average two or more functional groups per molecule ${ }^{6-8}$.

They are usually used as adhesives, coatings, foams and also as matrix resins for composites. The attractiveness of polyurethanes come from their excellent processability (low viscosity), excellent bonding to different substrates, absence of volatile organic compounds (VOC) and favorable economics.

It has been documented that the rate-of-load application affects the flexural properties of solid wood ${ }^{9}$, and that changes in strain rate affect the yield stress of plastics ${ }^{10}$.

*e-mail: jreis@id.uff.br
Increasing the strain rate leads to higher moduli because the polymer chains have reduced the relaxation time ${ }^{11-16}$

Repair and reinforce internally and externally corroded pipelines is one of the main application of such composite material system and therefore, understand its flexural behavior at different displacement rates is essential to proper execute the repair. The pipe or vessel segment is repaired by wrapping with concentric coils of composite material ${ }^{17}$ that is also submitted to flexion.

Composites made with polyurethane resins are widely used in various applications ranging from medical devices to automotive body panels. The success of polyurethane is due to its ability to be produced in various forms from flexible to rigid structures ${ }^{18,19}$. Knowledge in processing and advances in reactivity control to extend working time have placed polyurethane in the running for composite applications long dominated by unsaturated polyesters and vinyl esters ${ }^{20}$. In the last two decades, polyurethane composites made inroads primarily in foamed structural automotive interior and exterior parts. In the last years, polyurethane composites processes were highly developed. Primarily non-foamed, full-density polyurethane composite systems are being used with these traditional composite processes for applications from electric poles and automotive large parts to window lineals and bathtubs.

Understand the flexural behavior, strength and modulus and its predictions are essential to mechanical engineering proper design such material.

This study, therefore, aims to reveal the relationship between displacement rate, flexural stiffness and strength. First, the flexural stiffness was measured by the calculation of the modulus of elasticity and the prediction was performed. Simultaneously, the effect of the ultimate flexural strength was incorporated into the work. 


\section{Materials and Methods}

\subsection{Materials}

In this research the commercial product from Neptune Research Inc. (NRI) called Syntho-Glass $\mathrm{XT}^{\circledR}$ is used. It is a polyurethane pre-impregnated, bi-directional $\left(0^{\circ} / 90^{\circ}\right)$ E-glass fibre composite used to repair and reinforce internal and external corrosion on pipeline or structures is used to evaluate the flexural performance at different displacement rate. This composite is water-activated polyurethane resin, which reduces composite preparation time in 50\%. According to manufacturer gel time is 30 minutes and it is fully cured after 2 hours at $24^{\circ} \mathrm{C}$. Service temperature range from $-46^{\circ} \mathrm{C}$ to $90^{\circ} \mathrm{C}$ and it can be applied in environment conditions from $4^{\circ} \mathrm{C}$ to $65^{\circ} \mathrm{C}$.

\subsection{Methods}

Flexural test specimens were manufactured by hand lay-up. Each Syntho-Glass XT ${ }^{\circledR}$ pre-pag sheet has $0.33 \mathrm{~mm}$ and 15 layers were laminated to produce a $5 \mathrm{~mm}$ thickness plate. After 2 hours at $24^{\circ} \mathrm{C}$ the laminates are cured and coupons were water jet cutted in $250 \mathrm{~mm}$ x $25 \mathrm{~mm}$. Syntho-Glass XT ${ }^{\circledR}$ composites were tested in flexion at $23^{\circ} \mathrm{C}$ in a Shimadzu AGX-100 universal testing machine according to ASTM $\mathrm{D} 790^{21}$. Tests were performed at displacement rates of 0.2 ,
2, 20, 100, 200 and $1000 \mathrm{~mm} / \mathrm{min}$ in order to obtain the displacement rate dependency. For the tested material, five specimens were tested at a given rate. Flexural modulus was obtained from the initial slope of the stress-strain curve and the flexural strength from the maximum load. Figure 1 displays the 3 -point bending test setup.

\section{Results and Discussion}

Figure 2 presents the flexural stress vs. strain curves for glass fiber reinforced polyurethane obtained from the flexural tests performed with controlled displacement rates: $0.2,2,20,100,200$ and $1000 \mathrm{~mm} / \mathrm{min}$.

The behavior is linear until rupture of the first plies occurs. Then, the GFRP composites continue to retain energy until ultimate flexural strength is reached. After that, flexural strength start to decrease as laminate plies break. Nevertheless, both elasticity modulus and ultimate strength are rate-dependent (they tend to be higher for higher displacement rate). According to ASTM D79021, all the presented curves can be represented as curve $b$ where specimens yield and then break before the 5\% strain limit.

Table 1 presents the flexural test results of GFRP performed with controlled displacement rates of $0.2,2$, 20, 100, 200 and $1000 \mathrm{~mm} / \mathrm{min}$.

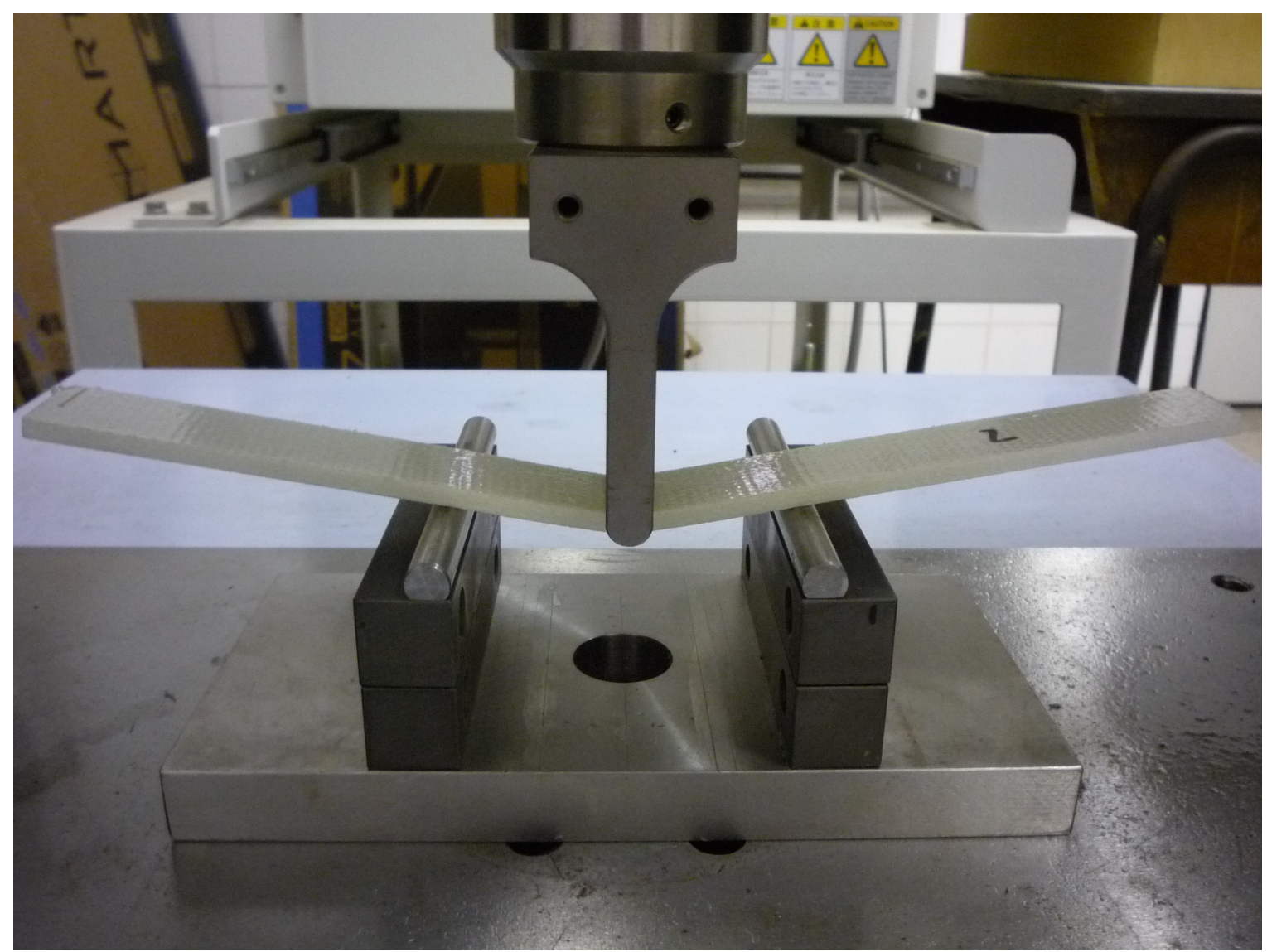

Figure 1. Flexural 3 point bending test setup. 
It is clear from Table 1 that the flexural stiffness and ultimate flexural strength are displacement rate dependent. As displacement rate increases, both modulus of elasticity and maximum tensile strength increase. On increasing the displacement rate from $0.2 \mathrm{~mm} / \mathrm{min}$ to $1000 \mathrm{~mm} / \mathrm{min}$ it is observed that there is an elevation of $37.4 \%$ in the modulus of elasticity and of $60.9 \%$ in the ultimate flexural strength.

Figure 3 displays the modulus of elasticity as a function of the displacement rate.

The dependence of the average flexural modulus of elasticity on the displacement rate can be estimated using a power function, as follows:

$$
E=14.089 \mathrm{R}^{0.0361}
$$

where $\mathrm{E}$ is the modulus of elasticity in GPa and $\mathrm{R}$ represents the displacement rate in $(\mathrm{mm} / \mathrm{min})$. As presented in figure 3, GFRP ultimate flexural strength is sensible to displacement rate variation. Figure 4 presents the ultimate flexural strength at different displacement rate.

The ultimate flexural strength behaves similar to the flexural modulus of elasticity, as a power function as displacement rate increases:

$U F S=198.02 \mathrm{R}^{0.0533}$

where UFS is the ultimate flexural strength in MPa and $\mathrm{R}$ represents the displacement rate in $(\mathrm{mm} / \mathrm{min})$.

Both flexural modulus of elasticity and ultimate flexural strength can be predict by the proposed equations within the range of the studied displacement rates, from $0.2 \mathrm{~mm} / \mathrm{min}$ to $1000 \mathrm{~mm} / \mathrm{min}$. Similar behavior in tension can be observed when the GFRP composites are tested in tension ${ }^{22}$. The tensile modulus of elasticity increases with the strain rate and higher ultimate tensile strengths are obtained for higher strain rates.

The influence of displacement speed on modulus and stress by tensile-shear test were analyzed by an One-Way ANOVA with a 0.05 significance level.

Firstly, the null hypothesis of residue normality was evaluated using Shapiro-Wilks and Levene's tests $(\alpha=0.05)$. For both, modulus and stress data, residue normality null hypothesis was not rejected $(p>0.05)$, as expected (modulus: Shapiro-Wilks $p=0.45 /$ Lilliefors $p=1$ and flexural stress: Shapiro-Wilks $p=0.44 /$ Lilliefors $p=1$ ). Secondly, homogeneity of variances was also evaluated for both sets using Brown-Forsythe and Levene's tests $(\alpha=0.05)$. Null hypothesis of homogeneity of variances was not rejected $(p>0.05)$, as expected (modulus: Brown-Forsythe $p=0.94 /$ Levene's $\mathrm{p}=0.54$ and flexural stress: Brown-Forsythe $p=0.79 /$ Levene's $p=0.50$ ).

Finally, the influence of displacement rate on modulus and flexural stress was evaluated. In both cases, modulus and stress, $p<0.05(p \rightarrow 0)$, showing that displacement rate influences both dependent variables for the adopted significance level of $\alpha=0.05$. Additionally, considering Fisher LSD analysis at $\alpha=0.05$, for modulus, displacement rate has led to dissimilar mechanical properties only for $0,2 \mathrm{~mm} / \mathrm{min}$ and stress presented similar flexural properties only for $100 \mathrm{~mm} / \mathrm{min}$ and $200 \mathrm{~mm} / \mathrm{min}$.
Table 1. Flexural results of GFRP at different displacement rates (avg \pm st. dev.)

\begin{tabular}{ccc}
\hline $\begin{array}{c}\text { Displacement } \\
\text { rate } \\
(\mathbf{m m} / \mathbf{m i n})\end{array}$ & $\begin{array}{c}\text { Modulus of elasticity } \\
\text { (GPa) }\end{array}$ & $\begin{array}{c}\text { Ultimate flexural } \\
\text { strength }(\mathbf{M P a})\end{array}$ \\
\hline 0.2 & $13.24 \pm 0.91$ & $180.79 \pm 8.73$ \\
2 & $14.62 \pm 0.71$ & $207.51 \pm 16.16$ \\
20 & $15.62 \pm 0.76$ & $234.72 \pm 11.52$ \\
100 & $16.46 \pm 1.26$ & $250.46 \pm 5.32$ \\
200 & $17.08 \pm 1.12$ & $257.18 \pm 15.24$ \\
1000 & $18.19 \pm 0.55$ & $290.98 \pm 14.30$ \\
\hline
\end{tabular}

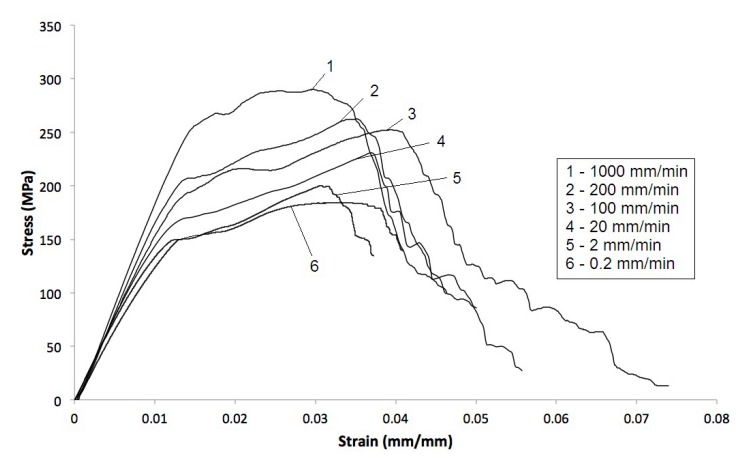

Figure 2. Flexural stress vs. strain curves of GFRP at different displacement rate.

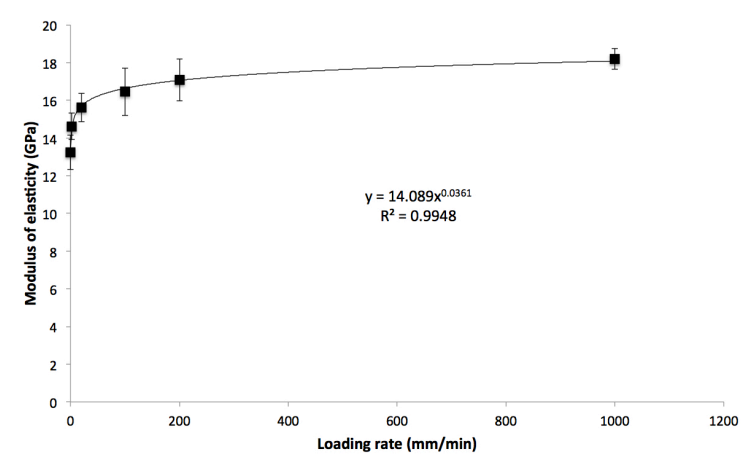

Figure 3. GFRP modulus of elasticity at different displacement rate.

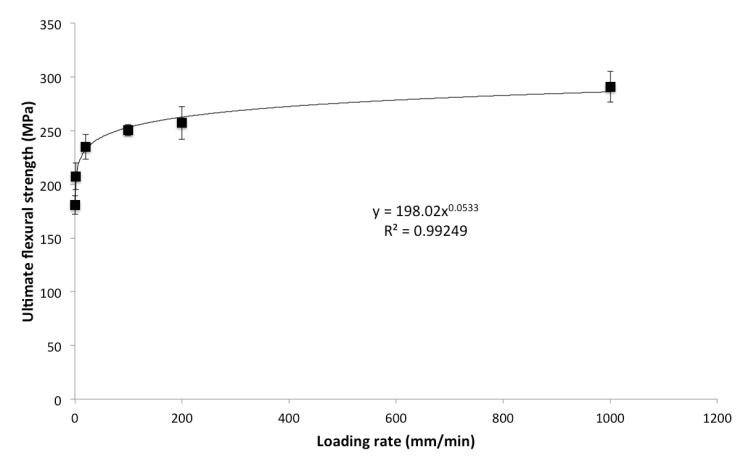

Figure 4. Displacement rate influence on the ultimate flexural strength of GFRP. 


\section{Conclusions}

Quasi-static and high displacement rate flexural tests were performed on glass fiber reinforced polyurethane. The experimental analysis shows that the mechanical response of this composite is strongly displacement rate dependent. The flexural modulus of elasticity increases with the displacement rate and higher ultimate strengths are obtained for higher displacement rates. Both modulus of elasticity and ultimate flexural strength can be represented by a power function. This study is a step to obtain a simple

\section{References}

1. Smith CS. Design of marine structures in composite materials. London: Elsevier Applied Science; 1990.

2. Mouritz AP, Gallagher J and Goodwin AA. Flexural strength and interlaminar shear strength of stitched GRP laminates following repeated impacts. Composites Science and Technology. 1997; 57(5):509-522.

3. Chiou BS and Shoen PE. Effect of crosslinking on thermal and mechanical properties of polyurethanes. Journal of Applied Polymer Science. 2002; 83:212-223.

4. John J, Bhattacharya M and Turner RB. Characterization of polyurethane foams from soybean oil. Journal of Applied Polymer Science. 2002; 86(12):3097-3107.

5. Desai S, Thakore IM, Sarawade BD and Devi S. Effect of polyols and diisocyanates on thermo-mechanical and morphological properties of polyurethanes. European Polymer Journal. 2000; 36(4):711-725

6. Delebecq E, Pascault JP, Boutevin B and Ganachaud F. On the versatility of urethane/urea bonds: reversibility, blocked isocyanate, and non-isocyanate polyurethane. Chemical Reviews. 2013; 113(1):80-118.

7. Javni I, Hong DP and Petrovic ZS. Polyurethanes from soybean oil, aromatic, and cycloaliphatic diamines by nonisocyanate route. Journal of Applied Polymer Science. 2013; 128(1):566571.

8. Ogunniyi DS, Fakayejo WR and Ola A. Preparation and properties of polyurethanes from toluene diisocyanate and mixtures of castor oil and polyol. Iranian Polymer Journal. 1996; 5:56-59.

9. Gerhard CC and Link CL. Effect of loading rate on bending strength of Douglas-fir 2 by 4's. Forest Products Journal. 1986; 36(2):63-66.

10. Hohfika YM and Stkori G. Temperature and strain rate independence of critical strains in polyethylene and poly(ethylene-co-vinyl acetate). Macromolecules. 2000; 33(5):1827-1833.

11. Hadal RS and Misra RD. The influence of loading rate and concurrent microstructural evolution in micrometric talc- and wollastonite-reinforced high isotactic polypropylene composites. Materials Science and Engineering A. 2004; 374(1-2):374-389. but effective failure criterion for composite reinforcement systems used for corroded pipelines in oil industry.

\section{Acknowledgements}

The authors would like to thank the Neptune Research Inc. (NRI) for providing the composites for testing, Research Foundation of the State of Rio de Janeiro (FAPERJ) and The Brazilian National Council for Scientific and Technological Development $(\mathrm{CNPq})$ for supporting part of the work presented here.

12. Brandt CW and Fridley KJ. Effect of load rate on flexural properties of wood-plastic composites. Wood and Fiber Science. 2003; 35(1):115-117.

13. Ramanathan T, Muthumanickam MA and Subramanian K. Study on the effect of loading rate on flexural strength of glass/ polyester composites as a function of span-to-depth ratio and fiber volume fraction. Materials and Manufacturing Processes. $2000 ; 15(6): 845-852$.

14. Sethi S, Rathore DK and Ray BC. Effects of temperature and loading speed on interface-dominated strength in fibre/polymer composites: an evaluation for in-situ environment. Materials \& Design. 2015; 65:617-626.

15. Ullah H, Harland AR and Silberschmidt VV. Characterisation of mechanical behaviour and damage analysis of 2D woven composites under bending. Composites. Part B, Engineering. 2015; 75:156-166.

16. Milanese AC, Cioffi MO and Voorwald HJ. Flexural behavior of sisal/castor oil-based polyurethane and sisal/phenolic composites. Materials Research. 2012; 15(2):191-197.

17. Costa-Mattos HS, Reis JM, Sampaio RF and Perrut VA. An alternative methodology to repair localized corrosion damage in metallic pipelines with epoxy resins. Materials \& Design. 2009; 30:3581-3591.

18. Saunders JH and Frisch KC. Polyurethanes: chemistry and technology. New York: Interscience Publishers; 1962.

19. Szycher M. Handbook of polyurethanes. Boca Raton: CRC Press; 1999.

20. Sherman LM. Polyurethane composites: new alternative to polyester and vinyl ester. Plastics Technology. March 2006 Available from: http://www.ptonline.com/articles/polyurethanecomposites-new-alternative-to-polyester-and-vinyl-ester. Access in: 19 Aug. 2015.

21. American Society for Testing and Materials - ASTM. ASTM D790-10: Standard test methods for flexural properties of unreinforced and reinforced plastics and electrical insulating materials. West Conshohocken: ASTM; 2010.

22. Reis JM, Chaves FL and Costa Mattos HS. Tensile behaviour of glass fibre reinforced polyurethane at different strain rates. Materials \& Design. 2013; 49:192-196. 